\title{
Mathematics in Education, Research and Applications

\section{Seminary projects in the process of obtaining mathematics knowledge, digital skills and time management competences}

\author{
Dana Országhová* \\ Slovak University of Agriculture in Nitra, Faculty of Economics and Management
}

\begin{abstract}
University study consists of a variety interconnected tasks that student must complete to pass exams. Seminary projects are part of the study of mathematical subjects and assessment of students' knowledge. In this paper, we analyze a set of seminary projects in mathematics, which students elaborated and sent for evaluation in electronic form. The main goal of the paper was to analyze the time interval of uploading projects into the university information system and to compare the score of particular projects. The approach of students to seminary projects in terms of time management was the basis for determining the uploading models using tools for expressing trends in MS Excel. Results of analysis confirmed that part-time students are able to use digital tools and methods of individual learning in the process of obtaining and development of mathematics knowledge.
\end{abstract}

KEYWORDS: mathematics knowledge, seminary projects, individual study, digital skills, time management

JEL CLASSIFICATION: I21, C02

\section{INTRODUCTION}

The aim of mathematical education in economic and managerial study programs is the theoretical and practical training of future graduates who will apply the acquired knowledge, professional expertise and creative thinking in solving practical problems. Quantitative and qualitative analysis of students' knowledge, evaluation of the impact of digital forms and methods of e-learning on students' knowledge are the subject of pedagogical research focusing on current issues of mathematics education.

Information technology (IT) and digital educational applications influence the course of the educational process and have brought many changes in the competencies of teachers and students [6]. Electronic forms and means of education bring new elements to the work of

\footnotetext{
* Corresponding author: doc. RNDr. Dana Országhová, CSc., Faculty of Economics and Management, Slovak University of Agriculture in Nitra, Tr. A. Hlinku 2, 94976 Nitra, e-mail: dana.orszaghova@uniag.sk
} 


\section{[MEPAA] Mathematics in Education, Research and Applications

teachers and enable to support students' activity in their studies [5], [8]. The development of competencies in a complex form is important in the context of expected changes in the professions and the employment of graduates in the near future [10]. During distance learning, digital competences come to the fore as an important factor in learning and acquiring knowledge [9]. Educators bring new possibilities of using information technology tools in the teaching various topics and acquiring knowledge with new methods [1]. Students have access to educational materials, electronic courses created in digital space, graphics and computer software [2], [7]. IT enables the creation of electronic materials and educational courses in mathematics in a logical sequence, the complexity of tasks to be adequately graded and the process of study systematically arranged. The results of the educational process are evaluated using various factors and include students' grades obtained in exams [4].

Electronic forms of education are supported by study materials in various forms, in educational platforms (e.g. university systems, LMS Moodle, MS Teams), e-learning includes e-mail communication, new educational and digital applications. The wealth of information and the digital learning environment requires students to have clearly defined priorities and deadlines. Universities provide support to their students through counseling centers on how to improve time management and create a plan with priorities in meeting tasks, projects and study goals (e.g. [3]).

Mathematical subjects are also included in the study programs of the Faculty of Economics and Management of the Slovak University of Agriculture in Nitra. Students will apply the acquired knowledge in application tasks and in the study of professional subjects. Distance learning during the coronavirus pandemic separated teachers and students, so it was necessary to include activities in mathematics that would support motivation to study. Seminary projects are among the methods that support active and individual study and are a means of individualizing education. Acquiring knowledge through seminary projects is the basis for successful completion of the course by exam. In this paper, we focused on the analysis of selected factors of seminary projects in mathematics, which were elaborated by students of economic study programs.

\section{MATERIAL AND METHODS}

Study subject Mathematics IA belongs to the group of obligatory subjects of bachelor study programs "Accounting" and "Business Management" that are provided by the Faculty of Economics and Management, the Slovak University of Agriculture in Nitra. Main source of research data was completed from mathematics seminary projects in the winter term of academic year 2021/2022. Research sample consisted of 31 students of the $1^{\text {st }}$ year in the parttime study.

During individual study they elaborated five seminary projects with these topics:

Assignment no. 1: Functions with one variable, graphs and features.

Assignment no. 2: Asymptotes of a function graph.

Assignment no. 3: Derivative of a function with one real variable.

Assignment no. 4: Application of derivative to find function monotonicity and local extremes. Assignment no. 5: Application of derivative to find function concavity and points of inflection. 


\section{[MERAA] Mathematics in Education, Research and Applications

For each assignment, the student could get a maximum of 10 points, a total of 50 points, which were part of the evaluation on the exam. At the beginning of the semester, students received detailed instructions from the teacher on how to process the seminary project, create an electronic version and upload it into the created repository in the University Information System (UIS) with deadline for submission. Students knew conditions about points score during the semester and how points are included in the evaluation in mathematics exam.

We analyzed students' mathematical knowledge through an average of project scores. Students had to apply digital skills to create an electronic version of the project. To evaluate the competencies of students in terms of time management, we used own methodological procedure, which is based on a comparison of the section 7 days before the deadline for inserting the project into the repository. We used MS Excel tools to determine uploading models for seminary projects.

\section{RESULTS AND DISCUSSION}

During distance learning in a time of coronavirus pandemic (March 2020 - December 2021), the mathematics seminar project became an important part of assessing students' knowledge. During the semester, students gradually study mathematical topics and elaborate seminary projects. Projects in the electronic version are placed in a designated repository (UIS), where they are accessible for evaluation by teacher. It is important for students to satisfy time conditions of the project, because it is not possible to upload the project after the deadline. In this case, the student must communicate with the teacher to justify the delay and with the consent of the teacher can submit the work by e-mail. Mentioned phases of the project work combine mathematics knowledge, digital skills and time management competencies.

As mentioned above, the students had to work out 5 assignments in the winter semester of 2021. Students received instructions from the teacher and knew conditions about projects elaborations. We analyzed the time period of 7 days when students entered assignments into UIS and we arranged the data according to the date of project submission. Students who submitted a project more than 7 days before the deadline are listed together in the value "Before" data. Students who, for various reasons, missed the deadline and apologized, were able to submit their work by e-mail. These students are listed together in the value "After".

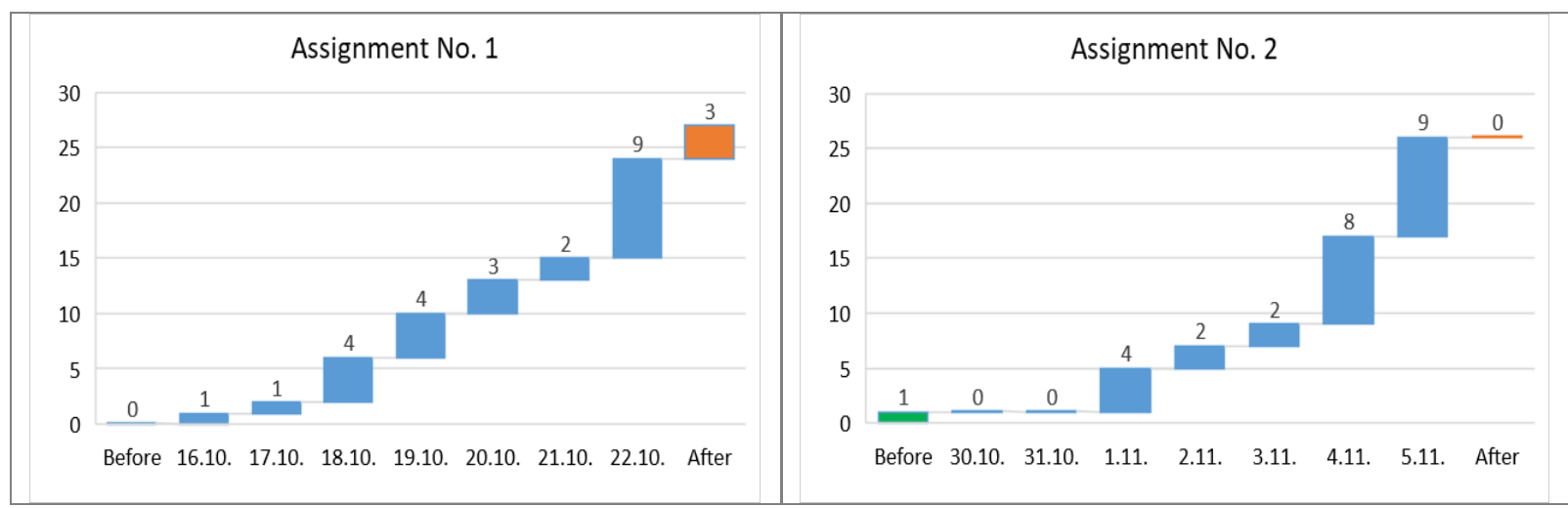

Figure 1 Days of uploads for projects ASS 1 Source: author

Figure 2 Days of uploads for projects ASS 2 Source: author 


\section{[MFRAA] Mathematics in Education, Research and Applications

Pictures (Fig. 1 - Fig. 5) show the graphical processing of the project submission time interval. Assignments are marked with the abbreviation ASS and with the serial number. We see that in all five cases the insertion of projects was gradual, while on the deadline the largest number of projects was uploaded into the repository (we remind, that each assignment was entered by a different number of students together).

- The first assignment ASS 1 was crucial for students. Within the first monitored 7 days' period the largest number of projects (9) was entered exactly on the deadline day. No student submitted the project more than 7 days before the deadline.

- In elaboration of ASS 2 students applied experience from the first project. We see the same number of projects uploaded on the deadline day (9, in comparison with ASS 1). And at the same time, we register the largest number of submitted projects one day before the deadline (8, out of all five seminary projects). In addition, no student submitted the ASS 2 after the defined deadline.

- When analyzing ASS 3 (and also ASS 5) we see 3 submitted assignments 7 days before the deadline.

- On the assignment ASS 4, we can mention these differences: the largest number of students submitted a project on the deadline day (12, out of all 5 projects). No one submitted the project until 7 days before the deadline.

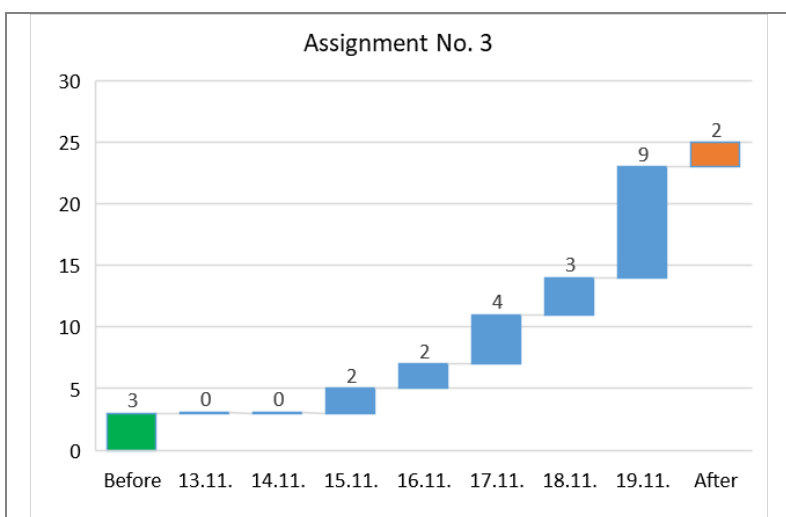

Figure 3 Days of uploads for projects ASS 3 Source: author
Assignment No. 4

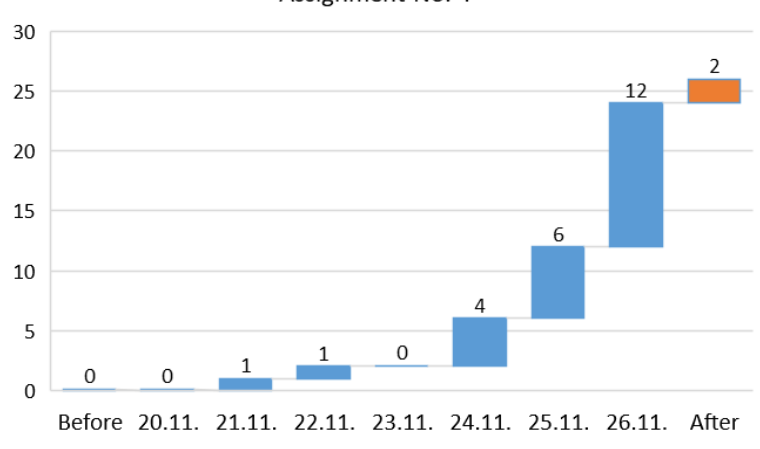

Figure 4 Days of uploads for projects ASS 4 Source: author

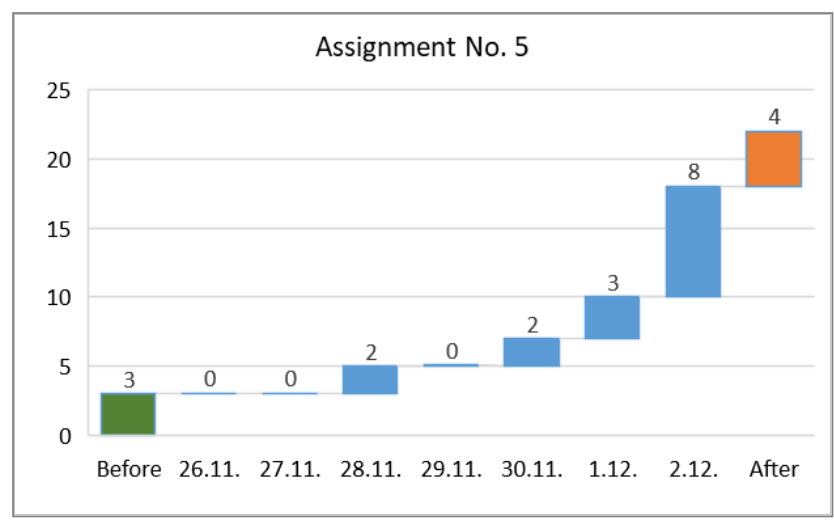

Figure 5 Days of uploads for projects ASS 5

Source: author 


\section{[MERA] Mathematics in Education, Research and Applications

- When elaborating ASS 5, students could apply all experience from previous assignments. On the deadline day, the largest number of assignments was entered again (8) and the largest number of students (4) submitted the assignment after the deadline (out of all 5 assignments).

To evaluate all assignments, we marked the period of 7 days as follows: the day of the deadline is $\mathrm{D}$ and gradually one day before the deadline is $1 \mathrm{D}$, two days before the deadline 2D, etc., up to 6 days for the deadline 6D. We merged the projects entered earlier (or later) together and included them at the beginning (or end) of the time interval. The number of submitted assignments 7 days before (or after) deadline D is in the data "Before" (or "After"). An overview of all submitted seminar projects, expressed in a percentage in relation to the day of submission, is shown in Fig. 6.

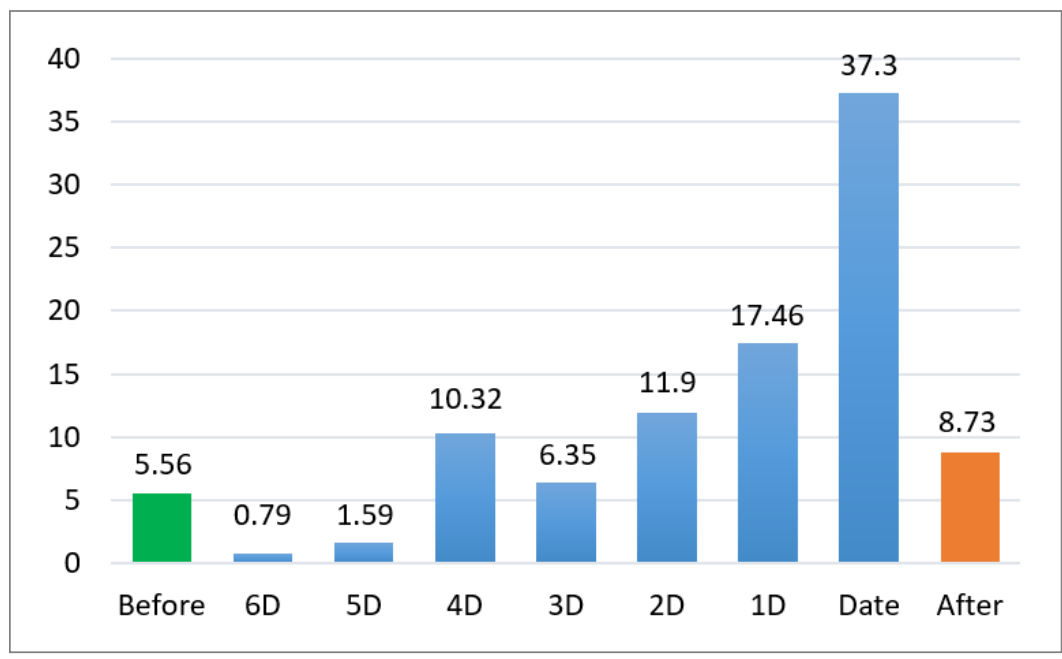

Figure 6 Days of uploads for all projects (in percentage)

Source: author

The analysis shows that most projects were submitted on the day of deadline D (37.3\%) and on day $1 \mathrm{D}$ before the deadline (17.46\% of projects), which is a total of $54.76 \%$ of all evaluated projects. There are also active students in the research group, as $5.56 \%$ of projects were submitted 7 days before the deadline. $8.73 \%$ of projects were submitted after the deadline. The reasons for the delay varied, from problems with technology, digital applications, file size, to the student's personal reasons.

The analysis of time data on the submission of seminary projects and the scoring of elaborated projects will help a teacher to find out how a group of students works on individual tasks. Using tools for expressing and displaying trends in MS Excel, we created two models for projects uploading with the prediction.

The first model M1 (Fig. 7) is based on data about all projects uploaded till the deadline (projects after deadline were excluded):

$$
\text { M1: } y=1.4583 x^{2}-8.1369 x+13.84 ; R^{2}=0.9036 \text {. }
$$

The model has increasing values, while $x$ is the day of submission. Students are submitting more projects as the date of deadline is approaching. 


\section{SMFRA Mathematics in Education, Research and Applications

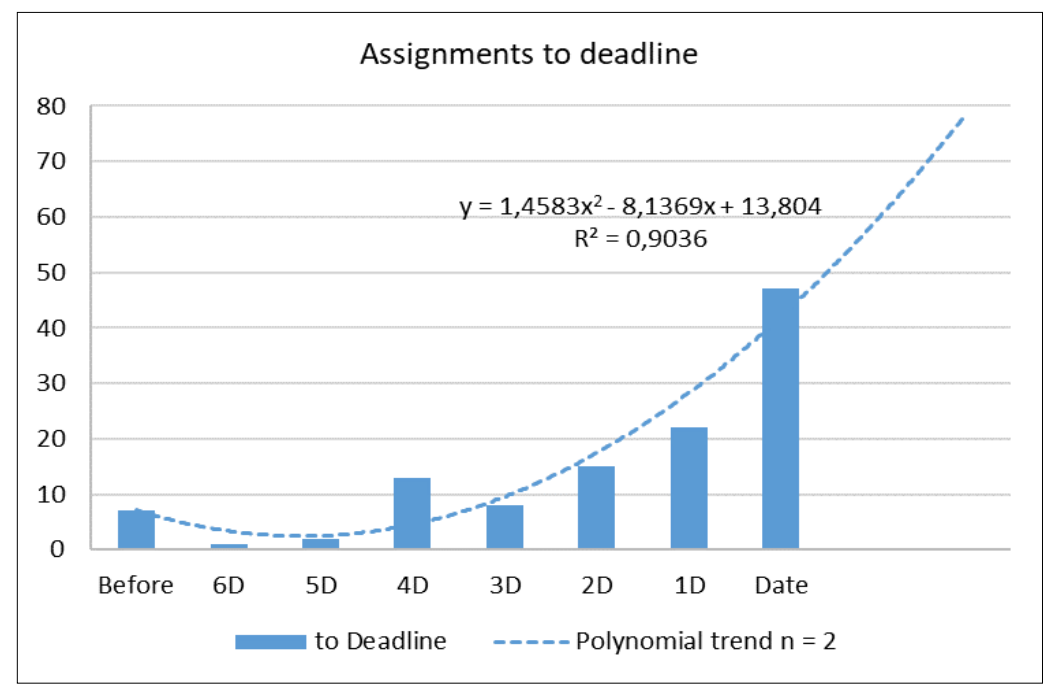

Figure 7 Uploading model M1 with trend line (projects uploaded to deadline) Source: author

The second model M2 (Fig. 8) is approximating data about projects submitted after deadline (with the permission of teacher):

$$
\text { M2: } y=0.5714 x^{2}-3.0286 x+5 ; R^{2}=0.9036 \text {. }
$$

The model is increasing, while $x$ is the serial number of assignment. Presented model does not include reasons of students for late project submission.

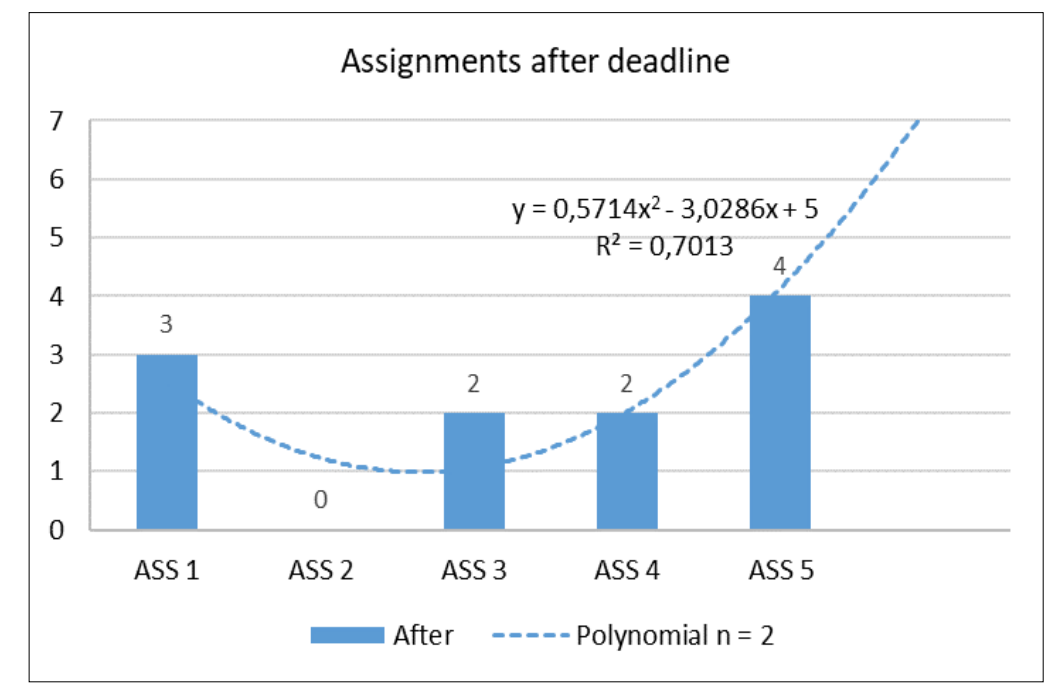

Figure 8 Model M2 with trend line (projects uploaded after deadline) Source: author

Each seminary project represents a test of these three factors: mathematical knowledge, digital skills of creating an electronic form of the project and time management activities. In the next part we present an analysis of the point score of students from the completed assignments, obtained on the basis of mathematical knowledge (Fig. 9). The average number of points from all submitted assignments is 9.05 (out of 10 possible points). We see that the obtained scores 


\section{IMFRAA] Mathematics in Education, Research and Applications

differ according to the particular assignments. The average number of points from the assignment ASS 1 is 8.63. Because this was the first seminary project, the students started to obtain necessary skills and achieved the least points.

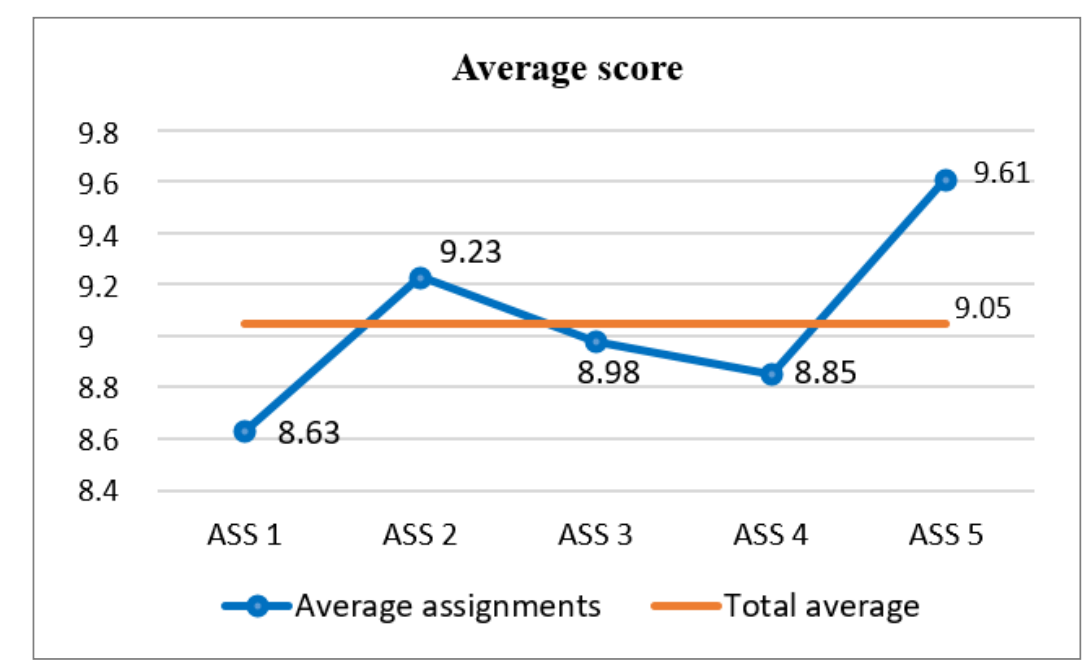

Figure 9 Average score in particular assignments and total average score Source: author

The second seminary project ASS 2 was on a topic that is new to university students. The average score of 9.23 indicates that students understood the topic and processed it with only minor errors. Assignments ASS 3 and ASS 4 again included new topics for students, the point score worsened compared to ASS 2. The average number of ASS 5 assignment is the highest of all (9.61), where students were motivated to get a good score for the exam. The content of ASS 5 followed the ASS 4, so students understood the mathematical method and solved the problems correctly.

Students have associated the submission of a seminary project with a certain amount of stress, whether tasks are solved correctly and whether the file will be uploaded to the repository correctly. Time management is very important for external students, because some of them also work or have their own family with children. The points score and the uploading time of projects will show the teacher what needs to be discussed with students. Find out what problems they had in elaborating and submitting the project (mathematical, technical, digital, time management, other) so that they could subsequently improve their preparation for the mathematics exam.

\section{CONCLUSIONS}

Seminary projects are a means of individual study and place demands on the student's selflearn skills. Seminary projects activate students, which is important in the educational process at the university. In this paper, we analyzed seminary projects in the study subject Mathematics IA, which were elaborated by first-year bachelor's students in the external form of study at the Faculty of Economics and Management, the Slovak University of Agriculture in Nitra. The content of the seminary projects included mathematical problems on the studied topics. Seminary projects are the part of the preparation for the exam and during their processing students gain new knowledge. 


\section{[MEPAA] Mathematics in Education, Research and Applications

The analysis shows that students have the knowledge and skills needed to elaborate a project. It is a combination of digital skills and time management competencies that have been used in the process of acquiring mathematical knowledge. From the point of view of time management, it follows that students solve projects and enter them into UIS gradually, even though the largest number of students entered the completed assignment on the last possible day. Obtained results are important for pedagogical communication, so that students could apply the necessary changes in the time management of projects, devote more time to the study of problematic topics and be able to obtain higher points in the mathematics exam.

\section{REFERENCES}

[1] Hlushak, O.M., Proshkin, V.V., \& Lytvyn, O.S. (2018). Using the e-learning course "Analytic Geometry" in the process of training students majoring in Computer Science and Information Technology. Proceedings of the 6th Workshop on Cloud Technologies in Education (CTE 2018), Kryvyi Rih, Ukraine, December 21, 2018. CEUR Workshop Proceedings 2433, 472-485. Retrieved 2021-10-21 from http://ceur-ws.org/Vol-2433/paper32.pdf

[2] Host’ovecký, M., Huraj, L., \& Pribilová, K. (2019). Virtual Reality in Mathematics: Design of the Serious Game Improves Spatial Imagination Performance. 17th International Conference on Emerging eLearning Technologies and Applications (ICETA) (pp. 239-244). IEEE.

[3] How to effectively manage and use your time? (2020). University Counselling Centre (UNIPOC), Pavol Jozef Šafárik University in Košice. Retrieved 2021-10-06 from https://www.upjs.sk/pracoviska/unipoc/aktuality/ako-efektivne-riadit-cas-2020

[4] Matušek, V., \& Hornyák Gregáňová, R. (2019). Comparison of exam results in Mathematics at Faculty of Economics and Management, Slovak University of Agriculture in Nitra. Mathematics in education, research and applications, 5(2), 78-83. doi: https://doi.org/10.15414/meraa.2019.05.02.78-83

[5] Mendonca, J., Nicola, S., \& Pinto, C. (2018). Active learning: self-motivation in math courses. Proceedings of 12th international technology, education and development conference (INTED), Valencia: Spain, 2018, pp. 1870-1877.

[6] Országhová, D., \& Hornyák Gregáňová, R. (2020). Evaluation of Mathematical Competences in Era of Skills Revolution. Nitra: Slovak University of Agriculture, 96 p. (in Slovak).

[7] Rumanová, L., \& Drábeková, J. (2017). View of teaching the mathematics of production possibilities curve. ICETC 2017. New York: The Association for Computing Machinery, 2017, 213-217.

[8] Smyrnova-Trybulska, E., Morze, N., Pavlova, T., Kommers, P.A., \& Sekret, I. (2017). Using effective and adequate IT tools for developing teachers' skills. International Journal of Continuing Engineering Education and Life Long Learning, 27(3), 219-245.

[9] Suchožová, E. (2014). Development and assessment of key competences in education process. Bratislava: Methodical and pedagogical center, 94 p. (in Slovak).

[10] The future of education and skills. Education 2030. (2018). Retrieved 2021-09-14 from https://www.oecd.org/education/2030/E2030\%20Position\%20Paper\%20(05.04.2018).pdf 